\title{
Study of asphaltene deposition from Tahe crude oil
}

\author{
CHEN Chaogang, ${ }^{1,2}$ GUO Jixiang ${ }^{1 *}$ AN Na ${ }^{1,3}$, REN Bo ${ }^{3}$, LI Yaguang ${ }^{1}$ and \\ JIANG Qingzhe ${ }^{1}$ \\ ${ }^{1}$ China University of Petroleum, Beijing 102249, China \\ ${ }^{2}$ Key Laboratory of Shale Gas Exploration, Ministry of Land and Resources, Chongqing Institute of Geology and Mineral \\ Resources, Chongqing 400042, China \\ ${ }^{3}$ Northwest Oilfield Branch Engineering and Technology Institute of Sinopec, Urumchi 830011, China
}

(C) China University of Petroleum (Beijing) and Springer-Verlag Berlin Heidelberg 2013

\begin{abstract}
Borehole blockage caused by asphaltene deposition is a problem in crude oil production in the Tahe Oilfield, Xinjiang, China. This study has investigated the influences of crude oil compositions, temperature and pressure on asphaltene deposition. The asphaltene deposition trend of crude oil was studied by saturates, aromatics, resins and asphaltenes (SARA) method, and the turbidity method was applied for the first time to determine the onset of asphaltene flocculation. The results showed that the asphaltene deposition trend of crude oil by the turbidity method was in accordance with that by the SARA method. The asphaltene solubility in crude oil decreased with decreasing temperature and the amount of asphaltene deposits of T739 crude oil (from well T739, Tahe Oilfield) had a maximum value at 60 ${ }^{\circ} \mathrm{C}$. From the PVT results, the bubble point pressure of TH10403CX crude oil (from well TH10403CX, Tahe Oilfield) at different temperatures can be obtained and the depth at which the maximum asphaltene flocculation would occur in boreholes can be calculated. The crude oil PVT results showed that at 50,90 and $130{ }^{\circ} \mathrm{C}$, the bubble point pressure of TH10403CX crude oil was $25.2,26.4$ and $27.0 \mathrm{MPa}$, respectively. The depth of injecting asphaltene deposition inhibitors for TH10403CX was determined to be $2,700 \mathrm{~m}$.
\end{abstract}

Key words: Onset of asphaltene flocculation, turbidity method, crude oil composition, temperature, bubble point pressure, borehole

\section{Introduction}

Crude oil is a stable colloidal system and asphaltene can dissolve in it under oil reservoir conditions, while in the oil production process, the stable state of crude oil will be disrupted due to changes in external conditions, resulting in deposition of asphaltenes. This is a severe problem in crude oil exploitation, and can cause substantial increase in production costs and affect the oil production due to frequent treatment and removal of asphaltenes. Reducing asphaltene deposits to a minimum level is a common goal for many oil companies (Akbarzadeh et al, 2004; Newberry and Barker, 1985; Akbar and Saleh, 1989), so it is of great importance to find out the reasons why asphaltene deposits in boreholes. Asphaltenes and resins in crude oil comprise its dispersed phase, while the remaining soluble fractions make up the continuous phase. Asphaltene deposition is closely related to the instability of the complex colloidal system, which is easily affected by temperature, pressure and crude oil composition, and any variation of these external conditions can lead to asphaltene deposition. Asphaltene flocculation is most likely

*Corresponding author. email: guojx002@163.com

Received March 18, 2012 to be the first step of asphaltene deposition (Leontaritis and Mansoori, 1987). In order to prevent or decrease asphaltene deposition, it is necessary to determine the flocculation onset and the possibility of asphaltene deposition.

The influence of crude oil composition on asphaltene deposition can be studied by adding $n$-alkanes to crude oil to reduce its stability and then determine the onset of asphaltene flocculation, when the ratio of $n$-alkanes to crude oil is used as a parameter for the stability of the colloidal system (Luo et al, 2007). Generally, the more stable the crude oil, the larger the amount of $n$-alkanes needed for flocculation. The methods for experimentally determining the onset of asphaltene flocculation include the interfacial tension method, filter drop spreading method (Carnahan et al, 1999), viscosity method (Li et al, 1997), spectrophotometry (Bartholdy and Andersen, 2000) and the electrical conductivity method (Li et al, 1998). Each of these methods has its merits and demerits, but until now, there has been no generally-accepted method for evaluating the onset of asphaltene flocculation (Zhao and Yan, 2003). The viscosity method is unsuitable for thin oil, while spectrophotometry can have a large measurement error due to crude oil color. The electrical conductivity method requires high precision high-sensitivity measurements, and is of low sensitivity for a crude oil with low asphaltenes 
content because of its low conductivity. In this paper, taking the advantages and disadvantages of the above methods into consideration, the turbidity method was chosen for determining the onset of asphaltene flocculation due to its independence of oil properties (such as oil color, etc.) and high reliability.

The principle of turbidity method for determining the onset of asphaltene flocculation: In the colloid disperse system of crude oil, the micelles are formed from asphaltene and resin molecules and each micelle is small. The stability of the colloid system is disrupted by adding $n$-alkanes to crude oil, leading to aggregation of asphaltene molecules and the formation of bigger particles, which result in flocculation and deposition of asphaltene. The size of the colloidal particles can be increased by 10 to 100 times in a short time during the aggregation of asphaltene micelles, resulting in the enhancement of the scattering of light waves in the colloid system, as a result, the turbidity value of the colloid system increases. Generally, the concentration of $n$-alkanes when the system turbidity begins to rise is regarded as the onset of flocculation.

\section{Experimental}

\subsection{Materials and instruments}

Materials: Oil samples from TH10403CX, TK1114CX, T739 and TP7 wells in the Tahe Oilfield, Xinjiang, China; $n$-heptane (AR); $n$-pentane (AR); petroleum ether $\left(90-120^{\circ} \mathrm{C}\right.$, AR).

Instruments: IATROSCAN MK-6s thin layer chromatogram quantitative analyzer (IATRON Company, Japan); Turb 550 turbidity detector (WTW Company, Germany); 2400.150 FV High temperature and high pressure PVT analyzer (Sanchez Technologies Company, France).

\subsection{Experimental methods}

\subsubsection{Analysis of crude oil group compositions}

The group compositions of crude oil were analyzed by thin layer chromatography according to China's oil and gas industry standard SY/T 5119-1995 "The Column Chromatography Analysis Method of the Rock Soluble Organic Matter and the Crude Oil Group Components".

\subsubsection{Prediction of crude oil stability}

1) SARA method

The possibility of asphaltene deposition was determined by the SARA method proposed by Newberry and Barker (2000). The SARA method uses Eq. (1) for calculating the colloid instable index $(C I I)$.

$$
C I I=\frac{w_{\text {saturates }}+w_{\text {asphaltenes }}}{w_{\text {resins }}+w_{\text {aromatics }}}
$$

where $w$ stands for the mass fraction of saturates, asphaltene, resins, and aromatics in crude oil, respectively.

When the $C I I$ value of crude oil is greater than or equal to 0.9 , asphaltene deposition is likely to occur.

2) Determination of asphaltene flocculation onset

The asphaltene flocculation onset was determined as follows: Mixtures of $n$-heptane and crude oil with different mass ratios were prepared and stirred uniformly, then the turbidity was measured with the turbidimeter. With an increase of the $n$-heptane content, the stability of the crude oil colloid system was gradually disrupted, increasing the turbidity. The asphaltene flocculation onset was obtained from curves with the turbidity value as ordinate and the mass ratio of $n$-heptane to crude oil as abscissa as in Figs. 1-4.

\subsubsection{Influence of temperature on asphaltene deposition}

Crude oil was added to a high-temperature and highpressure reaction vessel, and heated to 50,90 and $130{ }^{\circ} \mathrm{C}$, respectively, and then left at these temperatures for $24 \mathrm{~h}$, and the asphaltene deposited at the bottom of the reaction vessel. Then the content of $n$-heptane asphaltene in the upper crude oil was determined. The lower the asphaltene content in the upper crude oil, the greater the asphaltene deposits at the bottom of the reaction vessel from the initial crude oil.

2.2.4 Determination of the bubble point pressure of crude oil

The PVT parameters include formation temperature, dissolved gas-oil ratio, bubble point pressure, compressibility and viscosity of crude oil. Among them, bubble point pressure is an important parameter which affects asphaltene deposition.

The bubble point pressure was determined by using the PVT analyzer (Alboudwarej et al, 2002). P-V-T curves at different temperatures $\left(50,90\right.$ and $\left.130{ }^{\circ} \mathrm{C}\right)$ were plotted and the bubble point pressures at different temperatures were obtained from the P-V-T curves and the influence of bubble point pressure on asphaltene deposition was determined.

\section{Results and discussion}

\subsection{Analysis of crude oil group compositions}

Crude oil group compositions were determined by thin layer chromatography. The results are presented in Table 1.

Table 1 Analysis results of group compositions of crude oil (wt $\%$ )

\begin{tabular}{cccccc}
\hline Oil sample & Saturates & Aromatics & Resins & Asphaltenes & Total \\
\hline TK1114CX & 61.5 & 27.1 & 5.9 & 5.5 & 100 \\
T739 & 30.7 & 46.0 & 7.2 & 16.1 & 100 \\
TP7 & 40.1 & 44.4 & 6.4 & 9.1 & 100 \\
TH10403CX & 48.5 & 21.0 & 15.9 & 14.6 & 100 \\
\hline
\end{tabular}

As seen in Table 1, the contents of saturates and aromatics in the four oil samples were at the range of $30.7 \mathrm{wt} \%$ $61.5 \mathrm{wt} \%$ and $21.0 \mathrm{wt} \%-46.0 \mathrm{wt} \%$, respectively, which were relatively higher than the other two compositions. The resins and $n$-heptane asphaltene contents of the four oil samples were at the range of $5.8 \mathrm{wt} \%-15.8 \mathrm{wt} \%$ and $5.5 \mathrm{wt} \%-16.2 \mathrm{wt} \%$ respectively.

\subsection{Prediction of crude oil stability}

\subsubsection{SARA method}

The $C I I$ values of the four oil samples were calculated by the SARA method. As shown in Table 2, the CII values of oil 
samples TK1114CX, TH10403CX, and TP7 were all greater than 0.9 , indicating that in these three oil samples asphaltene deposition tends to occur due to their higher saturates and asphaltenes contents and lower aromatics and resins contents. The asphaltene deposition sequence of the four oil samples was TK1114CX $>\mathrm{TH} 10403 \mathrm{CX}>\mathrm{TP} 7>\mathrm{T} 739$. Among the four oil samples, the $C I I$ value of oil T739 was smaller than 0.9.

All the crude oil analyzed in this work was dead oil, that is, the ground condition is quite different from that of the reservoir, the pressure and temperature change subtantially when the crude oil is sampled from reservoir. Only analysis of live oil can accurately determine whether the asphaltene would deposit in the borehole or not by this method.

Table 2 Stability of crude oil

\begin{tabular}{ccc}
\hline Crude oil & CII & Stability \\
\hline TK1114CX & 2.03 & Unstable $(>0.9)$ \\
T739 & 0.88 & Stable $(<0.9)$ \\
TP7 & 0.97 & Unstable $(>0.9)$ \\
TH10403CX & 1.71 & Unstable $(>0.9)$ \\
\hline
\end{tabular}

\subsubsection{Determination of asphaltene flocculation onset}

The asphaltene flocculation onsets of oil samples were determined by the turbidity method and the results are shown in Figs. 1-4.

When the amount of $n$-heptane was not enough to disrupt the stability of the oil colloidal system, the turbidity value of the oil colloidal system was low. When the $n$-heptane to crude oil ratio reached a certain value the turbidity value increased sharply owing to large amount of asphaltene flocculated from crude oil (Andersen, 1999). Figs. 1-4 show that the asphaltene flocculation onsets of the four oil samples (TK1114CX, TH10403CX, TP7 and T739) appeared at an $n$-heptane to crude oil ratio (by weight) of 2.5, 6.0, 16 and 20, respectively. Therefore, the $n$-heptane to crude oil ratio (by weight) at which the turbidity value increases sharply is considered to be the asphaltene flocculation onset.

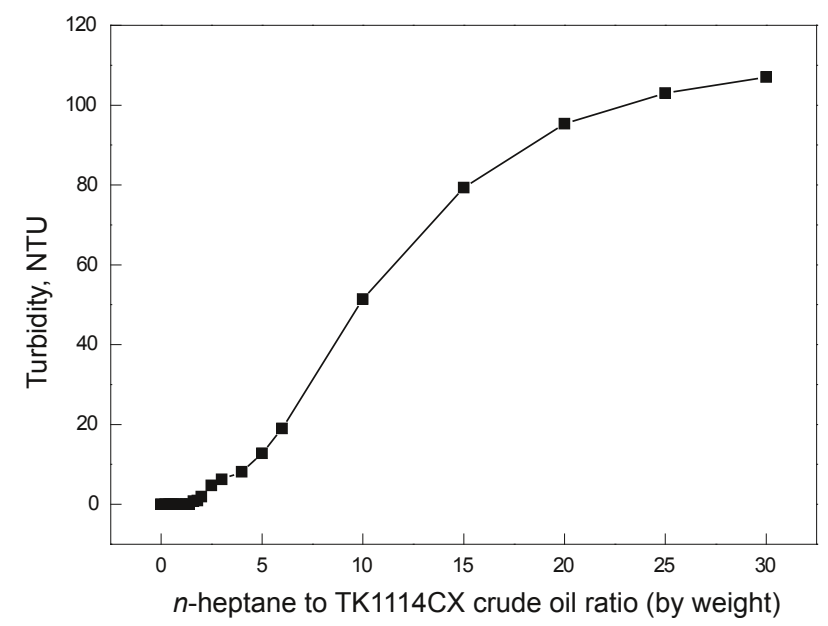

Fig. 1 Change of turbidity with $n$-heptane to TK1114CX crude oil ratio (by weight)
The asphaltene deposition possibility is related to the asphaltene flocculation onset and crude oil compositions. By the turbidity method, the asphaltene deposition sequence of the four oil samples was determined as: TK1114CX $>$ TH10403CX $>$ TP7 $>$ T739, which was in accordance with that obtained by the SARA method. Therefore, the turbidity method is a practicable approach for determining the asphaltene flocculation onset because of its simple operation and high reliability.

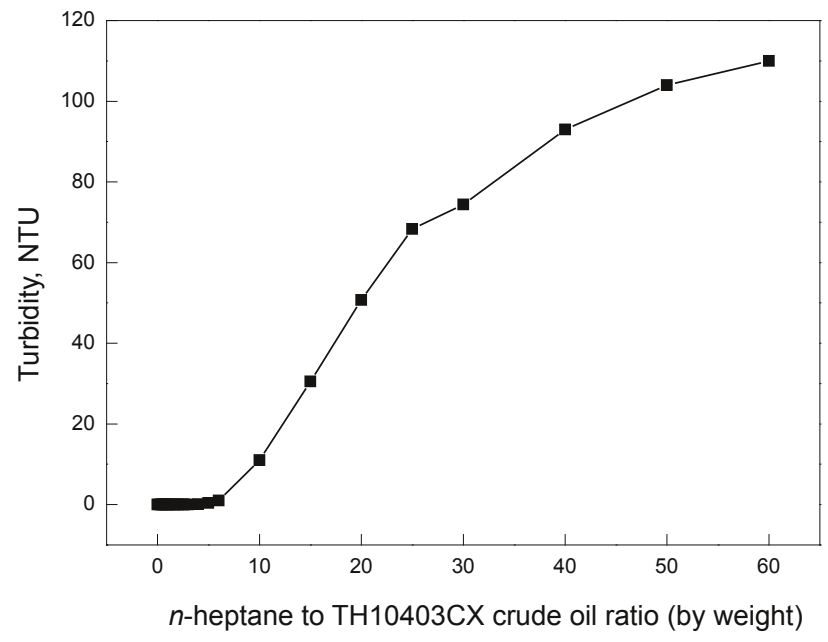

Fig. 2 Change of turbidity with $n$-heptane to TH10403CX crude oil ratio (by weight)

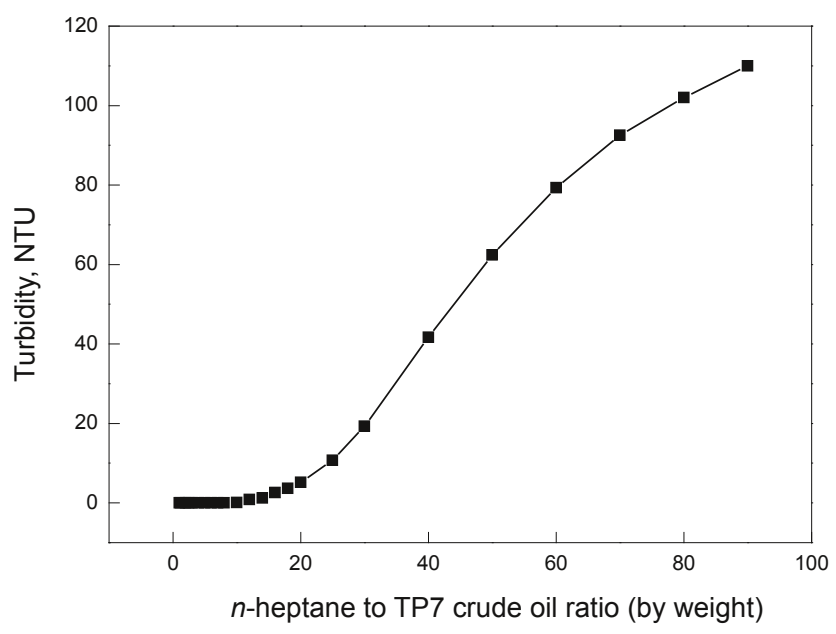

Fig. 3 Change of turbidity with $n$-heptane to TP7 crude oil ratio (by weight)

\subsection{Influence of temperature on asphaltene deposition}

The influence of temperature on asphaltene deposition is shown in Fig. 5 using T739 crude oil as an example. It can be seen that when the temperature was below $60{ }^{\circ} \mathrm{C}$, the amount of $n$-heptane asphaltene in crude oil decreased with increasing temperature, while when the temperature was above $60{ }^{\circ} \mathrm{C}$, the amount of $n$-heptane asphaltene in crude oil increased greatly with increasing temperature and had a minimum value at $60{ }^{\circ} \mathrm{C}$. 


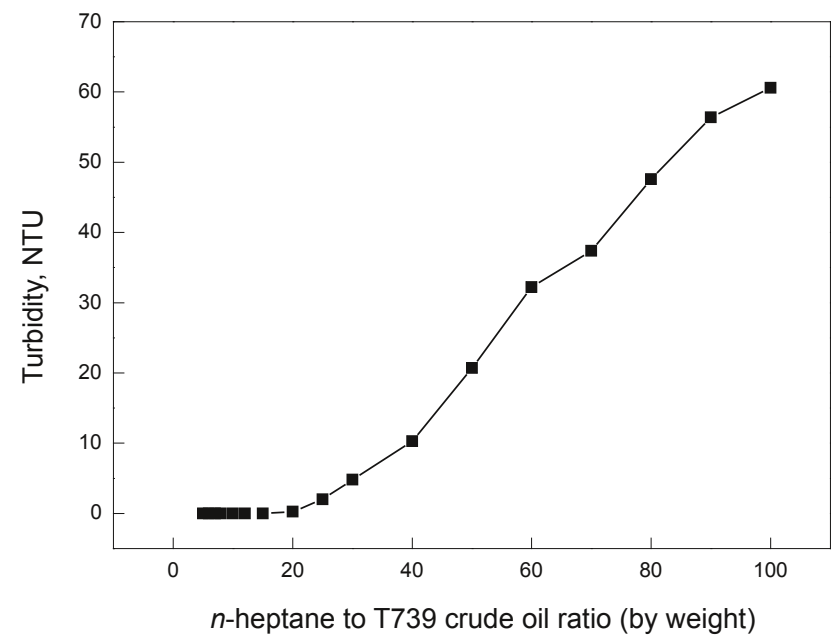

Fig. 4 Change of turbidity with $n$-heptane to T739 crude oil ratio (by weight)

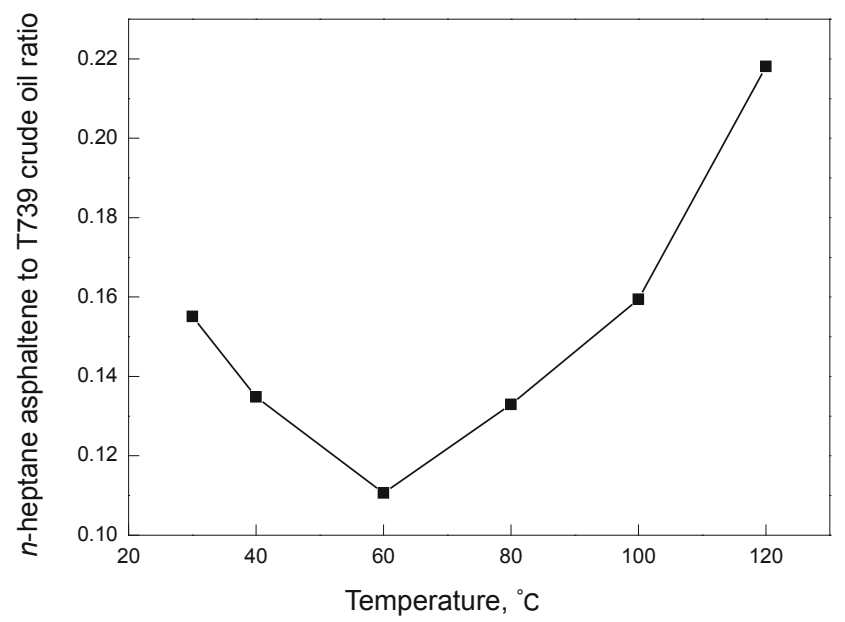

Fig. 5 Effect of temperature on $n$-heptane asphaltene deposition (T739 crude oil) with temperature

Temperature is one of the most important external factors influencing heavy organic deposition in oil-gas systems. Temperature reduces gradually in borehole lifting and asphaltene solubility decreases as well (Appleyard et al, 2009), asphaltene deposits from crude oil and is adsorbed on borehole surfaces at the asphaltene deposition point, affecting the crude oil flows. Therefore, it is necessary to control temperature in oil production to avoid asphaltene deposition.

\subsection{Crude oil bubble point pressure}

The P-V-T curves of TH10403 crude oil are shown in Fig. 6. The PVT results showed that at 50,90 and $130{ }^{\circ} \mathrm{C}$, the bubble point pressures of TH10403CX crude oil were 25.2, 26.4 and $27.0 \mathrm{MPa}$, respectively.

As shown in Fig. 6, the slope of P-V-T curves was small when the pressure is higher than the bubble point pressure, for the pressure has little effect on the volume of liquid phase. The slope of P-V-T curves became large when the pressure was lower than the bubble point pressure, due to the escape of gas from crude oil. Therefore, the pressure at the turning point of the curves is assigned to the bubble point pressure of the oil-gas system (Luo et al, 2007).

Pressure is another important factor affecting asphaltene deposition because it can influence crude oil composition (Chang and Fogler, 1993). Above the bubble point pressure, crude oil contains a large amount of light components and dissolved gas, both of which can act as the solvent of asphaltenes, thus asphaltene cannot deposit from crude oil. In the process of crude oil production, the pressure of crude oil decreases continuously from underground to the surface and the dissolved gases are released from crude oil at the bubble point pressure. In addition, the gas expansion process is an endothermic one, which leads to further oil temperature decrease, resulting in a decrease in the solubility of asphaltenes in the crude oil and asphaltene deposition. Bubble point pressure is an important parameter for determining the depth of injecting asphaltene deposition inhibitors in borehole (Afshari et al, 2010). For TH10403CX crude oil, the optimum depth of injecting asphaltene deposition inhibitors was 2,700 $\mathrm{m}$.

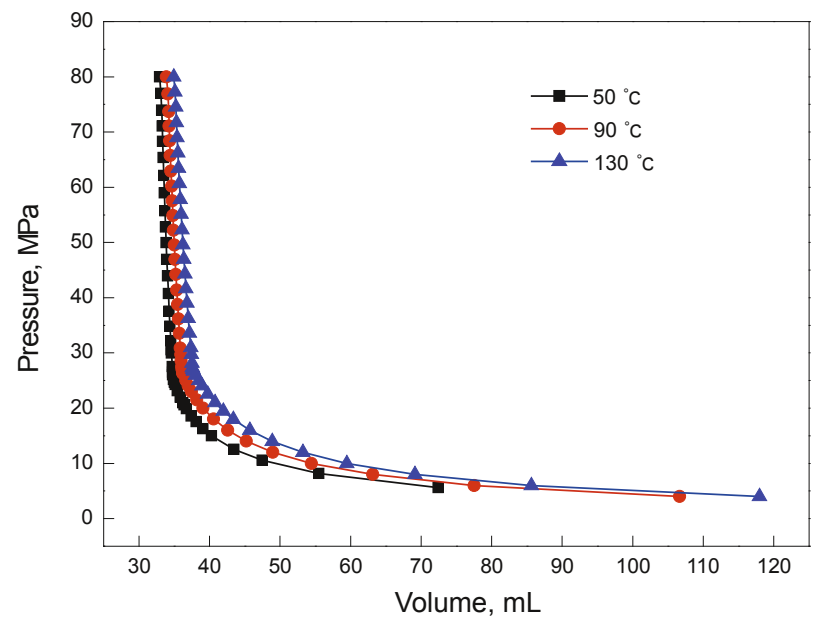

Fig. 6 P-V-T curves of TH10403 crude oil

\section{Conclusions}

1) The SARA method was adopted to calculate the colloid instability index (CII) of the four oil samples. The asphaltene deposition sequence of the four oil samples is TK1114CX> TH10403CX $>$ TP7 $>$ T739.

2) Asphaltene flocculation onsets of the four oil samples were determined by turbidity method and the asphaltene deposition of the four oil samples are in the following order: TK1114CX $>$ TH10403CX $>$ TP7 $>$ T739, which is in accordance with that obtained by SARA method.

3) The relationship of $n$-heptane asphaltenes and temperature was determined. The result shows that the asphaltene deposition of T739 crude oil is a maximum at 60 ${ }^{\circ} \mathrm{C}$.

4) The PVT parameters of TH10403CX crude oil were determined by FV PVT analyzer and the P-V-T curves were obtained. As shown in P-V-T curves, at 50, 90, and $130{ }^{\circ} \mathrm{C}$, the bubble point pressures of TH10403CX crude oil are 25.2, 
26.4 and 27.0 MPa, respectively. The depth above which asphaltene inhibitors are required in well TH10403CX is calculated to be $2,700 \mathrm{~m}$.

\section{Acknowledgements}

The authors would like to thank the National High Technology Research and Development Program of China (No. 2013AA064301), National Natural Science Foundation of China (No. 51274210) and 12th National Science and Technology Major Project of the Ministry of Science and Technology of China (No. 2011ZX05049-003-001-002) for financial support.

\section{References}

Afshari S, Kharrat R and Ghazanfari M H. Asphaltene precipitation study during natural depletion at reservoir conditions. CPS/SPE International Oil \& Gas Conference and Exhibition, 8-10 June 2010, Beijing (SPE 130071)

Akbar S H and Saleh A A. A comprehensive approach to solve asphaltene deposition problems in some deep wells. Middle East Oil Show, 11-14 March 1989, Bahrain (SPE 17965)

Akbarzadeh K, Sabbagh O, Beck J, et al. Asphaltene precipitation from bitumen diluted with $n$-alkanes. Canadian International Petroleum Conference, June 8-10, 2004, Calgary, Alberta, Canada (Paper 2004026)

Alboudwarej H, Svrcek W Y and Yarranton H W. PVT investigation of asphaltene precipitation and redissolution from bitumens. Canadian International Petroleum Conference, June 11-13, 2002, Calgary, Alberta, Canada (Paper 2002-015)

Andersen S I. Flocculation onset titration of petroleum asphaltenes. Energy \& Fuels. 1999. 13: 315-322

Appleyard S P, Cope D P, Gharfeh S G, et al. Prediction of asphaltene stability for live oils-impact of changes in temperature, pressure and composition. International Petroleum Technology Conference, 7-9
December 2009, Doha, Qatar (IPTC 13650)

Bartholdy J and Andersen I. Changes in asphaltene stability during hydrotreating. Energy \& Fuels. 2000. 14(1): 52-55

Carnahan N F, Salager J L and Antón R. Properties of resins extracted from Boscan crude oil and their effect on the stability of asphaltenes in Boscan and Hamaca crude oil. Energy \& Fuels. 1999. 13(2): 309314

Chang C L and Fogler H S. Asphaltene stabilization in alkyl solvents using oil-soluble amphiphiles. SPE International Symposium on Oilfield Chemistry, 2-5 March 1993, New Orleans (SPE 25185)

Leontaritis K J and Mansoori G A. Asphaltene flocculation during oil production and processing: A thermodynamic colloidal model. SPE International Symposium on Oilfield Chemistry, 4-6 February 1987, San Antonio, Texas (SPE 16258)

Li M X, Liu C G and Liang W J. Study of the deposition of asphaltene by electrical conductivity method. Acta Petrolei Sinica (Petroleum Processing Section). 1998. 14(4): 598-603 (in Chinese)

Li M X, Liu C G and Liang W J. Determination of the onset of asphaltene deposition by viscosity method. Journal of China University of Petroleum (Edition of Natural Science). 1997. 21(5): 75-78 (in Chinese)

Luo P, Kladkaew N and Gu Y. Detection of the onset of asphaltene precipitation in a heavy oil-solvent system. Canadian International Petroleum Conference, June 12-14, 2007, Calgary, Alberta, Canada (Paper 2007-096)

Newberry M E and Barker K M. Formation damage prevention through the control of paraffin and asphaltene deposition. SPE Production Operations Symposium, 10-12 March 1985, Oklahoma City, Oklahoma (SPE 13796)

Newberry M E and Barker K M. Organic formation damage control and remediation. SPE International Symposium on Formation Damage Control, 23-24 February 2000, Lafayette, Louisiana (SPE 58723)

Zhao F L and Yan J N. Determining the onset of asphaltenes flocculation in crude oil-A case of SZ36-1 oilfield. China Offshore Oil and Gas. 2003. 17(3): 186 (in Chinese)

(Edited by Zhu Xiuqin) 